\title{
EFEITO DO PROCESSAMENTO E ARMAZENAMENTO DE ALIMENTOS RICOS EM AMIDO SOBRE O ÍNDICE GLICÊMICO E RESPOSTA GLICÊMICA
}

\author{
ANA PAULA BORONI MOREIRA* \\ CERES MATTOS DELLA LUCIA* \\ ÉRICA AGUIAR MORAES** \\ RITA DE CÁSSIA GONÇALVES ALFENAS***
}

\begin{abstract}
Esta revisão de literatura teve como objetivo reunir informações a respeito do processamento e armazenamento de alimentos ricos em amido sobre o índice glicêmico e a resposta glicêmica. Foram abordados o conceito, a composição e as propriedades do amido, assim como do amido resistente. Tem sido evidenciada associação entre o consumo dos alimentos que promovem baixa resposta glicêmica e a prevenção de doenças crônicas não transmissíveis. Neste sentido, alguns métodos de processamento e armazenamento têm sido sugeridos como alternativas capazes de reduzir a resposta glicêmica dos alimentos ricos em amido. Concluiu-se que esforços na tentativa de se modificar a estrutura do amido podem constituir alternativa para se reduzir o índice glicêmico dos alimentos e devem ser incentivados para a promoção da saúde.
\end{abstract}

PALAVRAS-CHAVE: AMIDO - PROCESSAMENTO; AMIDO - ARMAZENAMENTO; RESPOSTA GLICÊMICA; AMIDO RESISTENTE.

* Doutorandas em Ciência da Nutrição, Departamento de Nutrição e Saúde, Universidade Federal de Viçosa (UFV), Viçosa, MG, Brasil (e-mails: ana.boroni@ufv.br; ceresnut@yahoo.com.br).

** Mestre em Ciência da Nutrição, Departamento de Nutrição e Saúde, UFV, Viçosa, MG, Brasil (e-mail: erica_moraes12@hotmail.com).

*** Doutora em Nutrição pela Purdue University, Professora Associada, Departamento de Nutrição e Saúde, UFV, Viçosa, MG, Brasil (e-mail: ralfenas@ufv.br). 


\section{INTRODUÇÃO}

As taxas de digestão e absorção apresentadas pelos carboidratos afetam as respostas glicêmica e insulinêmica pós-prandiais, as quais podem ser determinantes para o controle metabólico de algumas doenças crônicas não transmissíveis (DCNT) (JENKINGS et al., 2002; SHARMA e YADAV, 2008). Por esta razão, cresceu o interesse a respeito dos efeitos biológicos dos carboidratos no organismo humano (FAO/WHO, 1998; LAJOLO e MENEZES, 2001; JENKINGS et al., 2002).

O índice glicêmico (IG), parâmetro utilizado para classificar os alimentos de acordo com a resposta glicêmica que promovem em relação à resposta observada após o consumo de alimento referência (glicose ou pão branco), avalia indiretamente a disponibilidade in vivo de carboidratos (WOLEVER et al., 1991; FAO/WHO, 1998; BROUNS et al., 2005).

Vários fatores podem influenciar a velocidade de digestão e/ou de absorção, resultando em diferenças no IG dos alimentos. Os principais fatores que interferem nesse parâmetro incluem: o estágio de maturação das frutas, a forma física apresentada pelo alimento, a composição do alimento (quantidade de carboidratos, proteínas, lipídeos, fibras e conteúdo de água), o tipo de amido (amilose e amilopectina), o tipo de processamento ao qual o alimento foi submetido, acidez, volume e temperatura do alimento ingerido, além do estado fisiológico apresentado pelo indivíduo (FAO/WHO, 1998; CARVALHO e ALFENAS, 2008).

Em relação ao tipo de amido, verifica-se que grânulos crus quando gelatinizados, durante o cozimento, são rompidos aumentando a sua suscetibilidade à degradação enzimática (HOLM et al., 1988). Entretanto, o resfriamento do amido submetido ao calor úmido resulta no processo de retrogradação, o qual aumenta a sua resistência às enzimas digestivas, podendo reduzir o seu IG (FREDRIKSSON et al., 2000; FREI, SIDDHURAJU e BECKER, 2003).

Os resultados de vários estudos têm evidenciado os efeitos benéficos do consumo de dietas com baixo IG em indivíduos saudáveis e em portadores de DCNT, como obesidade, diabetes, doenças cardiovasculares e alguns cânceres (BUYKEN et al., 2001; FRANCESCHI et al., 2001; AUGUSTIN et al., 2002; HU et al., 2006). A prevalência de DCNT cresce mundialmente e estima-se aumento ainda maior nos próximos anos (BARRETO et al., 2005; LOW, CHIN e DEURENBERGYAP, 2009; IKEOKA, MADER e PIEBER, 2010). Neste sentido, há grande interesse entre os pesquisadores quanto à identificação de estratégias dietéticas capazes de promover a saúde e assegurar a qualidade de vida da população (MARINHO, HAMANN e LIMA, 2007). Assim, o objetivo deste trabalho foi revisar o efeito do processamento e armazenamento de alimentos ricos em amido sobre o IG e a resposta glicêmica.

\section{METODOLOGIA}

Realizou-se pesquisa bibliográfica nas bases de dados Pubmed, Science Direct, Scielo, HighWire Press e periódicos da Capes, além de outras fontes consideradas relevantes. Os descritores utilizados foram: amido, amido resistente, processamento de alimentos, estocagem de alimentos, índice glicêmico e seus correspondentes em inglês.

\section{AMIDO}

O amido constitui o carboidrato de reserva energética mais comum em vegetais, incluindo as sementes, frutas, tubérculos e raízes. Trata-se da fonte mais importante de carboidrato na alimentação humana (SINGH, DARTOIS e KAUR, 2010). O amido, polímero relativamente simples, é composto de moléculas de glicose que estão ligadas entre si de duas formas diferentes: amilose e amilopectina (Figura 1). A amilose constitui de 20 a 30\% do amido, sendo uma molécula linear 
em que as unidades de glicose são unidas por ligações $\alpha(1 \rightarrow 4)$. Já a amilopectina, o principal componente do amido (70 a 80\%), têm cadeias ramificadas, pois apresenta ligações $\alpha(1 \rightarrow 4)$ nas cadeias e $\alpha(1 \rightarrow 6)$ nos pontos de ramificações, além de maior massa molecular (JOBLING, 2004; SINGH, DARTOIS e KAUR, 2010). A proporção de amilose e amilopectina presentes no grânulo de amido difere em função da fonte botânica, variedades da mesma espécie de planta e, até na mesma variedade, de acordo com o grau de maturação da planta (TESTER, KARKALAS e QI, 2004).

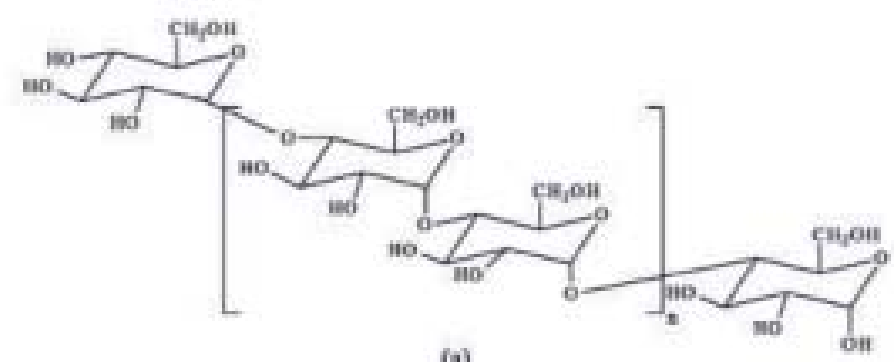

(a)

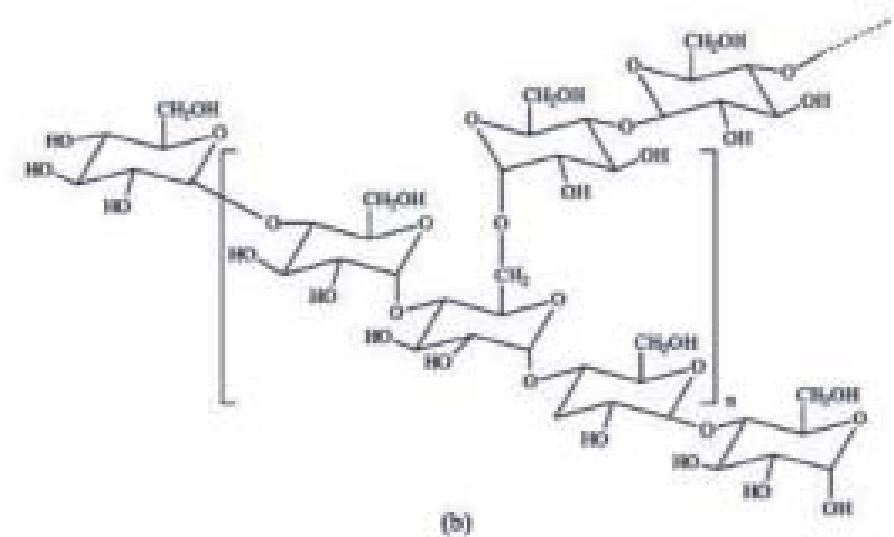

\section{FIGURA 1 - ESTRUTURA DO AMIDO: (A) ESTRUTURA LINEAR DA MOLÉCULA DE AMILOSE COM LIGAÇÕES $\alpha(1 \rightarrow 4)$; (B) ESTRUTURA RAMIFICADA DA MOLÉCULA DE AMILOPECTINA COM LIGAÇÕES $\alpha(1 \rightarrow 4)$ E $\alpha(1 \rightarrow 6)$}

Amilose e amilopectina apresentam diferentes propriedades. A natureza química da amilose permite a formação de complexos com pequenas moléculas de natureza hidrofóbica, como no amido de cereais, nas quais está complexada com lipídeos, o que pode reduzir a degradação do amido por enzimas (BALL e MORELL, 2003). Já a estrutura ramificada da amilopectina permite maior espaçamento entre as moléculas, facilitando a entrada de água que, por sua vez, carreia com grande facilidade as enzimas digestivas. Desta forma, não somente as extremidades, mas todo o grânulo sofre o ataque enzimático ao mesmo tempo, liberando rapidamente grandes quantidades de glicose (TESTER, KARKALAS e QI, 2004; BROUNS et al., 2005; SINGH, DARTOIS e KAUR, 2010).

As propriedades mais importantes com influência no valor nutricional do amido incluem a taxa e a extensão da digestão ao longo do trato gastrointestinal e o metabolismo dos monômeros absorvidos (LOBO e SILVA, 2003). Um dos métodos mais utilizados para classificar os amidos baseia-se na cinética de digestão in vitro, sugerido por Englyst, Kingman e Cummings (1992). Assim, de acordo com a velocidade com a qual o alimento é digerido, o amido classifica-se como rapidamente digerível quando converte-se em glicose em 20 minutos; lentamente digerível quando converte-se em glicose em 120 minutos; e amido resistente. 


\subsection{AMIDO RESISTENTE}

O amido resistente é um componente natural da dieta, sendo que seu consumo médio equivale a aproximadamente $3 \mathrm{~g} / \mathrm{dia}$. É encontrado em alimentos não processados como grãos, batata crua, banana verde ou mesmo em alimentos processados e retrogradados como a casca de pão ou a batata cozida resfriada (SLAVIN, 2004; PEREIRA, 2007; RAMOS, LEONEL e LEONEL, 2009).

Em 1982, Englyst, Wiggins e Cummings sugeriram pela primeira vez o termo amido resistente. Verificaram que alimentos processados continham maior concentração aparente de polissacarídeos não amiláceos (celulose, hemicelulose e pectina) do que os produtos crus correspondentes. Análises mais específicas demonstraram que a maior concentração ocorria em função da formação de compostos de $n$-glicose, que podiam ser dispersos em hidróxido de potássio, sendo resistentes à dispersão em água fervente. Deste modo, definiram amido resistente como sendo aquele que além de apresentar as propriedades anteriormente citadas, resiste à hidrólise pela ação da amilase pancreática. Essa fração era constituída, principalmente, de amilose retrogradada, que também parecia ser altamente resistente à digestão (CHAMP e FAISANT, 1996). No entanto, a partir do ano de 1992, a definição de amido resistente, assumiu nova denotação relacionando-se aos seus efeitos biológicos, compreendendo a soma do amido e dos produtos de sua degradação que não são absorvidos no intestino delgado de indivíduos saudáveis, podendo ser fermentados no intestino grosso (FAISANT et al., 1993; EERLINGEN e DELCOUR, 1995; GOÑI et al., 1996).

$\mathrm{O}$ amido resistente pode ser classificado em quatro tipos (ENGLYST, KINGMAN e CUMMINGS, 1992). No Tipo I, a forma física do alimento pode impedir o acesso da amilase pancreática e diminuir a digestão do amido. Isto ocorre quando o amido está contido em estrutura inteira ou parcialmente rompida da planta (como nos grãos); quando as paredes celulares rígidas inibem o seu intumescimento e dispersão (como nos legumes); ou por sua estrutura densamente empacotada (WALTER, SILVA e EMANUELLI, 2005; FUENTES-ZARAGOZA et al., 2010). O amido resistente do Tipo Il compreende o grânulo nativo do amido, encontrado no interior da célula vegetal, que está protegido da digestão devido às características intrínsecas da estrutura cristalina dos seus grânulos, como em batatas cruas, bananas verdes e amidos com elevadas concentrações de amilose (LOBO e SILVA, 2003; NUGENT, 2005). O Tipo III consiste na fração de amido não digerida, formada a partir de tratamentos hidrotérmicos que causam a retrogradação do amido. Já amido resistente, pertencente ao Tipo IV, envolve o grupo de amido que foi quimicamente modificado de modo a diminuir sua digestibilidade (NUGENT, 2005; FUENTES-ZARAGOZA et al., 2010).

A maioria dos alimentos fonte de amido ingerida pelo homem precisa ser submetida a tratamentos térmicos associados, frequentemente, à umidade. Esse processamento da matéria resulta, normalmente, no rompimento da estrutura do amido causado pela gelatinização, aumentando sua suscetibilidade para a digestão e absorção pelo intestino delgado (BOTHAM et al., 1995). Assim, o processamento de alimentos, que envolve a aplicação de calor e umidade, resulta na formação do amido do tipo III (FARAJ, VASANTHAN e HOOVER, 2004). Esse tipo de amido é geralmente formado durante a retrogradação dos grânulos de amido (FUENTESZARAGOZA et al., 2010). A retrogradação ocorre com o resfriamento e envelhecimento do amido gelatinizado, formando nova estrutura parcialmente cristalina mais ordenada, insolúvel e resistente à digestão enzimática, porém apresentando conformação diferente da inicial (THOMPSON, 2000; HERNÁNDEZ, EMALDI e TOVAR, 2008; LIU et al., 2009). Outros fatores também podem levar à formação de amido resistente tipo III: a) repetidos ciclos de aquecimento e resfriamento; b) fonte botânica do amido (tubérculos ou cereais), a qual influencia a relação amilose/amilopectina (à temperatura ambiente, quanto maior o teor de amilose, mais rápida e pronunciada será a formação de amido resistente, devido à estrutura linear de sua molécula) (GOÑI, GARCIA- 
ALONSO e GARCIA, 1995); e c) quantidade de água utilizada durante a gelatinização, ou seja, quanto mais água, maior será a taxa e a extensão da retrogradação (ESCARPA e GONZÁLEZ, 1997; FREDRIKSSON et al., 1998; THOMPSON, 2000).

O aumento da utilização de amido resistente pela indústria alimentícia é relevante, uma vez que representa ingrediente que não causa alterações sensoriais tão pronunciadas quanto as fontes tradicionais de fibra. No entanto, o principal interesse pelo amido resistente se deve aos seus potenciais efeitos fisiológicos benéficos (YUE e WARING, 1998; SAJILATA e SINGHAL, 2005; WALTER, SILVA e EMANUELLI, 2005; BAIXAULI et al., 2008). O consumo de amido resistente tem sido relacionado com a prevenção de DCNT como o câncer de cólon (WALTER, SILVA e PERDOMO, 2005), obesidade (KEENAN et al., 2006) e diabetes (HAUB et al., 2010), além de efeito hipocolesterolemiante (HAN et al., 2003).

O amido resistente, juntamente com os polissacarídeos não amiláceos (celulose, hemicelulose e pectina) e os oligossacarídeos resistentes (frutooligossacarídeos e inulina) são considerados como carboidratos não glicêmicos (ENGLYST e ENGLYST, 2005). O amido resistente contribui para a redução do IG dos alimentos, proporcionando menor resposta glicêmica e, consequentemente, menor resposta insulínica. Desta forma, pode melhorar o controle metabólico do diabetes, principalmente do tipo 2 . Além disso, a não digestão do amido resistente no intestino delgado permite que esses carboidratos alcancem o intestino grosso e sejam fermentados pelas bactérias colônicas, produzindo ácido graxos de cadeia curta (acetato, propionato e butirato) (FUENTES-ZARAGOZA et al., 2010; HAUB et al., 2010). Os ácidos graxos produzidos, principalmente o butirato, são absorvidos através da mucosa intestinal e utilizados como substratos energéticos pelos colonócitos, além de exercerem efeito trófico sobre a mucosa intestinal (HAMER et al., 2008). Em função desse efeito no organismo, o amido resistente foi considerado pelo Institute of Medicine (IOM, 2005) como fibra funcional, a qual consiste de carboidratos que, quando isolados, exercem efeito benéfico ao indivíduo.

As reduções das respostas glicêmicas a partir do consumo de amido resistente tipo II e IV foram demonstradas por Haub et al. (2010) quando comparadas com o controle de dextrose. Esses autores verificaram também, que os diferentes tipos de amido resistente provocam respostas glicêmicas distintas. A resposta glicêmica ocasionada pelo consumo de amido resistente do tipo IV foi $23,4 \%$ menor que a causada pelo amido resistente do tipo II.

Embora estudos demonstrem os efeitos benéficos associados ao consumo de diferentes quantidades e tipos de amido resistente sobre as respostas glicêmicas e insulinêmicas, seus resultados são ainda controversos (CARREIRA, LAJOLO e MENEZES, 2004; SHARMA e YADAV, 2008). Por exemplo, altos valores de IG foram verificados em humanos após o consumo de cereais matinais que, conhecidamente, contêm significativas concentrações de amido retrogradado (TRUWELL, 1992).

A indústria de alimentos tem se apoiado nas modificações da estrutura do amido para a obtenção de alimentos com baixo IG (JOBLING, 2004; FERNANDES, VELANGI e WOLEVER, 2005). Nesse sentido, alguns métodos de processamento e armazenamento estão sendo apontados como alternativas para reduzir o impacto dos alimentos com alto IG na glicemia e insulinemia.

\section{PROCESSAMENTO E ARMAZENAMENTO DO AMIDO VS RESPOSTA GLICÊMICA E IG}

As respostas glicêmica e insulinêmica são variáveis para alimentos ricos em carboidratos, mesmo quando a quantidade de carboidrato ingerido permanece constante. A adição de fibras solúveis aos alimentos fonte de carboidrato pode reduzir as respostas glicêmica e insulinêmica por aumentarem a viscosidade dos mesmos (COLLINGS, WILLIAMS e MACDONALD, 1981). 
A cocção úmida não só aumenta a viscosidade, como também quebra os grânulos de amido, aumentando sua disponibilidade à amilase. Collings, Williams e MacDonald (1981) pesquisaram as respostas glicêmica e insulinêmica do amido cru e submetido à cocção. Nesse estudo, onze estudantes saudáveis do sexo masculino receberam de forma aleatória e após o jejum noturno $1 \mathrm{~g}$ de equivalente de glicose $/ \mathrm{kg}$ de peso corporal na forma de amido de milho cru ou cozido $(0,91 \mathrm{~g} / \mathrm{kg}$ de peso corporal) ou glicose monoidratada $(1,1 \mathrm{~g} / \mathrm{kg}$ de peso corporal) em $4 \mathrm{~mL}$ de água/ $/ \mathrm{kg}$ de peso corporal. $\mathrm{O}$ cozimento do amido cru ocorreu em água à temperatura de $68-70^{\circ} \mathrm{C}$, sob agitação, até completa formação do gel. $\mathrm{O}$ amido cru e a água foram ingeridos como pasta e a glicose monoidratada como solução. Amostras de sangue foram coletadas antes da ingestão (0 minuto) e 15, 30, 60 e 90 minutos após a ingestão da refeição teste. As respostas glicêmicas à glicose monoidratada e ao amido cozido foram muito semelhantes, enquanto que as do amido cru mostraram-se significativamente menores. A área abaixo da curva insulinêmica foi significativamente maior após a refeição contendo glicose monoidratada em relação à refeição composta por amido cozido que, por sua vez, mostrou-se significativamente maior que a refeição contendo amido cru. De acordo com os autores, a natureza diferente da resposta glicêmica para amido cru e cozido pode ter ocorrido pela menor disponibilidade do amido cru à amilase ou pela diferença na viscosidade das duas refeições teste (amido cru e cozido) (COLLINGS, WILLIAMS e MACDONALD, 1981). No entanto, as menores respostas glicêmica e insulinêmica para o amido cru sugerem que a alteração na viscosidade não foi o fator responsável. Assim, parece que a capacidade de alterar a resposta glicêmica ou insulinêmica, ou ambas, numa refeição rica em carboidratos não é peculiar a certos tipos de fibra alimentar, mas também pode ser provocada pelo cozimento.

Alimentos crus ganharam popularidade porque quando consumidos frescos, inteiros e sem tratamento térmico, são boas fontes de vitaminas e minerais. Além disso, alimentos ricos em amido e não cozidos podem ter o IG relativamente baixo, já que não foram submetidos ao processo de cocção (SAKUMA et al., 2009).

O processo de cocção, capaz de perturbar a estrutura do amido, pode aumentar as respostas glicêmica e insulinêmica porque o rompimento da estrutura do amido causado pela gelatinização aumenta sua suscetibilidade para a digestão e absorção pelo intestino delgado (HOLM et al., 1988; SHARMA e YADAV, 2008).

A estrutura apresentada pelos alimentos ricos em amido também desempenha importante papel na resposta pós-prandial. Alimentos como centeio, aveia, trigo e cevada resultam em baixas respostas glicêmica e insulinêmica. No entanto, quando a matéria-prima é triturada antes de ser cozida ocorre aumento da área de contato com o trato gastrointestinal, que eleva a velocidade de digestão e absorção, podendo aumentar as respostas glicêmica e insulinêmica (ALMINGER e EKLUND-JONSSON, 2008; JUNG et al., 2009).

Jung et al. (2009) testaram a hipótese de que o arroz cru (que tem nível relativamente baixo de gelatinização) poderia resultar em menor resposta nos metabolismos glicêmico e insulinêmico em comparação com arroz cozido (ACoz). Para avaliar os efeitos da gelatinização de arroz sobre o metabolismo de glicose e de insulina, os autores investigaram as respostas glicêmica e insulinêmica de estudantes do sexo feminino $(n=12)$ em 3 refeições compostas por arroz em diferentes graus de gelatinização: ACoz (76,9\% gelatinização), arroz em pó cru (APC: $3,5 \%$ gelatinização) e arroz em pó cru e liofilizado (APL: 5,4\% gelatinização). A liofilização diminui o teor de umidade de produtos alimentares devido à sublimação, o que influencia o grau de hidratação do amido e, portanto, o grau de gelatinização (HICKMAN, JANASWAMY e YAO, 2009). Os resultados obtidos demonstraram que o arroz em pó (APC e APL) acarretou menores respostas glicêmica e insulinêmica em comparação ao ACoz. O grau relativamente baixo de gelatinização do arroz em pó cru resultou em menores IG (ACoz: 72,4 vs APC: 49,7; APL: 59,8). Em suma, o arroz em pó cru que era menos gelatinizado que o arroz cozido, induziu menores respostas glicêmica pós-prandial e insulinêmica. 
Carreira, Lajolo e Menezes (2004) avaliaram a influência do armazenamento de alimentos sob baixa temperatura $\left(-20^{\circ} \mathrm{C}\right)$ e formação de amido resistente sobre o IG de alimentos apenas cozidos ou cozidos e armazenados a $-20^{\circ} \mathrm{C}$ por 30 dias. Foi evidenciado aumento significativo no conteúdo de amido resistente para todos os alimentos estudados. $\mathrm{O}$ armazenamento dos alimentos resultou em redução significativa no IG do feijão e do grão de bico. Já o IG do macarrão permaneceu o mesmo e o IG do fubá de milho aumentou. Portanto, observaram que a formação de amido resistente pode levar à redução do IG. $O$ armazenamento de alimentos ricos em amido sob baixa temperatura pode colaborar com a ingestão de amido resistente, mas o seu efeito sobre - IG dependerá das características dos carboidratos de cada alimento, uma vez que os teores de amilose e amilopectina variam.

Tahvone et al. (2006) tiveram como objetivo comparar o efeito do processamento industrial e do armazenamento sob refrigeração por 3 ou 4 dias de produtos de batata. Vinte e dois voluntários saudáveis (13 homens e 9 mulheres) foram divididos em dois grupos (grupo 1 e grupo 2). Quatro refeições teste e uma refeição contendo o alimento de referência $(50 \mathrm{~g}$ glicose em $300 \mathrm{~mL}$ de água) foram fornecidas ao grupo 1 e três refeições teste e uma refeição contendo o alimento de referência (50 g glicose em $300 \mathrm{~mL}$ de água) foram fornecidas ao grupo 2 durante 5 semanas. As respostas glicêmicas foram avaliadas após período de jejum de pelo menos 8 horas, sendo a refeição da noite anterior padronizada. As coletas de sangue ocorreram nos tempos $0,15,30,45$, 60, 90 e 120 minutos após a ingestão da refeição teste ou do alimento de referência. As refeições teste consistiram de: a) Batatas frescas contendo, em média, 13,5\% de amido e em porções de tamanho suficiente para fornecer $50 \mathrm{~g}$ de carboidrato disponível; b) Batatas frescas cozidas a vapor por 30 a 40 minutos; c) Batatas em cubos (batatas frescas descascadas, imersas em solução de metabissulfito de sódio e estocadas em sacos plásticos). No dia seguinte, as batatas foram cortadas em cubos e cozidas a vapor em caçarolas. Os cubos foram refrigerados por 3 dias e servidos frios; d) Caçarola 1: batatas frescas descascadas, imersas em solução de metabissulfito de sódio e estocadas em sacos plásticos. No dia seguinte, as batatas foram cortadas em cubos, cozidas a vapor em caçarolas e assadas em forno de convecção a $175^{\circ} \mathrm{C}$ por 1 hora. Depois de prontas, as batatas foram mantidas quentes até o momento de servir; e) Caçarola 2: preparadas de acordo com o procedimento anterior, com a diferença de que, depois de assadas, as batatas foram resfriadas a $5^{\circ} \mathrm{C}$ e estocadas por 3 dias. Antes de serem servidas, as batatas foram reaquecidas a $70-80^{\circ} \mathrm{C}$ em forno de convecção e mantidas quentes até o momento de servir; f) Caçarola 3: batatas frescas descascadas, imersas em solução de metabissulfito de sódio e estocadas em sacos plásticos. No dia seguinte, foram cozidas a vapor, amassadas e assadas sob a forma de purê em caçarolas a $150^{\circ} \mathrm{C}$ por 1 hora. Posteriormente, foram resfriadas a $5^{\circ} \mathrm{C}$ por 4 dias. Antes de ser servida, a preparação foi reaquecida a $70-80^{\circ} \mathrm{C}$ em forno de convecção e mantida quente até o momento de servir; g) Caçarola 4: preparada conforme o item anterior, com tempo de assamento de 50 minutos e servidas de forma similar; e h) Caçarola 5: preparadas semelhantemente ao procedimento anterior. As batatas foram cozidas a vapor e amassadas. Posteriormente, foram congeladas sem passar pela cocção. Após 14 dias, as batatas foram descongeladas e reaquecidas a $70-80^{\circ} \mathrm{C}$ em forno de convecção e mantidas quentes até o momento de servir. O IG e a área abaixo da curva de resposta glicêmica foram significativamente menores para as batatas em cubos (batatas cozidas, resfriadas e servidas frias) quando comparados à caçarola 1 (batatas fatiadas, servidas imediatamente) e à caçarola 5 (purê de batatas, congelado e reaquecido). O resfriamento continuou apresentando efeito, mesmo depois do reaquecimento, uma vez que o IG da caçarola 2 (batatas cozidas, resfriadas e reaquecidas) foi significativamente menor que o da caçarola 1 (servida quente depois de assada). $O$ ato de amassar (purê) ou fatiar a batata não produziu diferenças no IG. Os resultados desse estudo indicam a ocorrência de mudanças significativas na estrutura do amido durante o resfriamento e a estocagem a frio (nesse caso, por 3 ou 4 dias).

Os resultados obtidos por Tahvone et al. (2006) podem ser devidos ao fato de parte do amido 
gelatinizado sofrer retrogradação durante o armazenamento, sendo esse fenômeno mais rápido em baixas temperaturas, uma vez que as pontes de hidrogênio são mais fortes em temperaturas frias (SHAMAI, BIANCO-PELED e SHIMONI, 2003). A retrogradação da amilose torna-se mais rápida em temperatura próxima a $1^{\circ} \mathrm{C}$, e cerca de $20 \%$ da fécula de batata é geralmente constituída de amilose. A amilopectina apresenta menor retrogradação em condições convencionais de processamento de alimentos (TAHVONE et al., 2006).

Akerberg et al. (1998) encontraram aumento no teor de amido resistente em batatas cozidas quando foram armazenadas a $5^{\circ} \mathrm{C}$ por $24 \mathrm{~h}$. Os autores utilizaram método in vitro para analisar o amido resistente, mimetizando o processo digestivo.

Sucessivos ciclos de resfriamento e reaquecimento aumentaram a quantidade de amido resistente em testes in vitro, de acordo com Kingman e Englyst (1994). Alguns autores (KINGMAN e ENGLYST, 1994; GARCIA-ALONSO e GOÑI, 2000) sugerem a formação de amido resistente do tipo III quando as batatas são armazenadas em geladeira após temperaturas de fervura ou cozimento. Desse modo, o processo de resfriamento e a armazenagem a frio de alimentos industrializados à base de batata parece ser favorável para a redução do IG.

\section{CONCLUSÃO}

Os carboidratos exercem papel fisiológico essencial no organismo humano, sendo que as taxas de digestão/absorção e, consequentemente, as respostas glicêmica/insulinêmica apresentadas pelos mesmos podem ser determinantes para o controle metabólico de algumas DCNT. Por esse motivo, o interesse sobre a utilização biológica dos carboidratos pelo organismo tornou-se crescente, especialmente em relação ao amido resistente.

A obtenção de amido resistente por meio de alguns métodos de processamento e armazenamento de alimentos tem demonstrado importância não só na indústria para produção de alimentos de alta qualidade, mas também por resultar em menores respostas glicêmica e insulinêmica pós-prandiais. Esforços na tentativa de se modificar a estrutura do amido ou o método de preparação tradicional dos alimentos ricos em amido podem constituir perspectiva para se reduzir o IG dos alimentos e devem ser incentivados.

\section{ABSTRACT \\ EFFECT OF PROCESSING AND STORAGE OF STARCHY FOODS ON THE GLYCEMIC INDEX AND GLYCEMIC RESPONSE}

This literature review aimed to gather information regarding the processing and storage of starchy foods and its effect on the glycemic index and glycemic response. Were addressed the concept, composition and properties of starch and resistant starch. An association between the consumption of foods that promote low glycemic response and the prevention of chronic diseases has been verified. In this sense, some methods of processing and storage have been suggested as alternatives that can reduce the glycemic response of starchy foods. It was concluded that efforts on trying to change the structure of starch may be an alternative to reduce the glycemic index of foods and should be encouraged to promote health.

KEY-WORDS: STARCH-PROCESSING; STARCH-STORAGE; GLYCEMIC RESPONSE; RESISTANT STARCH.

\section{REFERÊNCIAS}

1 AKERBERG, A.K.E.; LILJEBERG, H.G.M.; GRANFELDT, Y.E.; DREWS, A.W.; BJORCK, I.M.E. An "in vitro" method, based on chewing, to predict resistant starch content in foods allows parallel determination of potentially available starch and dietary fiber. J. Nutr., v.128, p.651-660, 1998.

2 ALMINGER, M.; EKLUND-JONSSON, C. Whole-grain cereal products based on a high-fibre barley or oat genotype lower post-prandial glucose and insulin responses in healthy humans. Eur. J. Nutr., v.47, p.294300, 2008. 
3 AUGUSTIN, L.S.; FRANCESCHI, S.; JENKINS, D.J.; KENDALL, C.W.; LA VECCHIA, C. Glycemic index in chronic disease: a review. Eur. J. Clin. Nutr., v.56, p.1049-1071, 2002.

4 BAIXAULI, R.; SALVADOR, A.; MARTINEZ-CERVERA, S.; FISZMAN, S. M. Distinctive sensory features introduced by resistant starch in baked products. Food Sci. \& Technol., v.41, p.1927-1933, 2008.

5 BALL, S.G.; MORELL, M.K. From bacterial glycogento starch: understanding the biogenesis of the plant starch granule. Annu. Rev. Plant. Biol., v.54, p. 207-233, 2003.

6 BARRETO, S.M.; PINHEIRO, A.R.O.; SICHIERI, R.; MONTEIRO, C.A.; BATISTA FILHO, M.; SCHIMIDT, M.I. et al. Análise da estratégia global para alimentação, atividade física e saúde da Organização Mundial da Saúde. Epidemiol. Serv. Saúde, v. 14, p. 41-68, 2005.

7 BOTHAM, R.L.; CAIRNSA, P.; MORRISA, V.J.; RINGA, S.G.; ENGLYSTB, H.N.; CUMMINGSB, J.H. A physicochemical characterization of chick pea starch resistant to digestion in the human small intestine. Carbohyd. Polym., v.26, p.83-90, 1995.

8 BROUNS, F.; BJORCK, I.; FRAYN, K.N.; GIBBS, A.L.; LANG, V.; SLAMA, G. et al. Glycemic index methodology. Nutr. Res. Rev., v.18, p. 145-171, 2005.

9 BUYKEN, A.E.; TOELlER, M.; HEITKAMP, G.; KARAMANOS, B.; ROTTIERS, R.; MUGGEO, M. et al. Glycemic index in the diet of European outpatients with type 1 diabetes: relations to glycated hemoglobin and serum lipids. Am. J. Clin. Nutr., v.73, p.574-581, 2001.

10 CARREIRA, M.C.; LAJOLO, F.M.; MENEZES, E.W. Glycemic index: effect of food storage under low temperature. Braz. Arch. Biol. Technol., v.47, n.4, p.569-574, 2004.

11 CARVALHO G.Q.; ALFENAS R.C.G. Índice glicêmico: uma abordagem crítica acerca de sua utilização na prevenção e no tratamento de fatores de risco cardiovasculares. Rev. Nutr., v.21, n.5, p.577-587, 2008.

12 CHAMP, M.; FAISANT, N. Resistant starch: analytical and physiological aspects. Bol. SBCTA, v.30, n.1, p. 37-43, 1996.

13 COLLINGS, P.; WILLIAMS, C.; MACDONALD, I. Effects of cooking on serum glucose and insulin responses to starch. Brit. Med. J., v.282, p.28, 1981.

14 EERLINGEN, R. C.; DELCOUR. Formation, analysis, structure and properties of type III enzyme resistant starch. J. Cereal Sci., v.22, p.129-138, 1995.

15 ENGLYST, H.N.; WIGGINS, H.S.; CUMMINGS, J.H. Determination of the non-starch polysaccharides in plant food by gas-liquid chromatography of constituent sugars as alditol acetates. Analyst, v.107, p.307318, 1982.

16 ENGLYST, H.N.; KINGMAN, S.M.; CUMMINGS, J.H. Classification and measurement of nutritionally important starch fractions. Eur. J. Clin. Nutr., v.46, n.2, p.33- 50, 1992.

17 ENGLYST, K. N.; ENGLYST, H.N. Carbohydrate bioavailability. Brit. J. Nutr., v. 94, p.1-11, 2005.

18 ESCARPA, A.; GONZÁLEZ, M. C. Tecnología del almidón resistente. Food Sci. \& Technol. Int., v. 3, p.149-161, 1997.

19 FAISANT, N.; CHAMP, M.; COLONNA, P.; BULÉON, A. Structural discrepancies in resistant starch obtained in vivo in humans and in vitro. Carbohyd. Polym., v. 21, p. 205-209, 1993.

20 FARAJ, A.; VASANTHAN, T.; HOOVER, R. The effect of extrusion cooking on resistant starch formation in waxy and regular barley flours. Food Res. Int., v.37, p.517-525, 2004.

21 FERNANDES, G.; VELANGI, A.; WOLEVER, T.M.S. Glycemic index of potatoes commonly consumed in North America. J. Am. Diet Assoc., v. 105, p.557-562, 2005.

22 FOOD AND AGRICULTURAL ORGANIZATION/WORLD HEALTH ORGANIZATION (FAO/WHO). Carbohydrates in human nutrition. Rome, 1998. 140 p. (Food and Nutrition Paper). 
23 FRANCESCHI, S.; DAL MASO, L.; AUGUSTIN, L.; NEGRI, E.; PARPINEL, M.; BOYLE, P. et al. Dietary glycemic load and colorectal cancer risk. Ann. Oncol., v.12, p.173-178, 2001.

24 FREDRIKSSON, H.; SILVERIO, J.; ANDERSSON, R.; ELIASSON, A. C.; AMAN, P. The influence of amylase and amylopectin characteristics on gelatinization and retrogradation properties of starches. Carbohyd. Polym., v.35, p. 119-134, 1998.

25 FREDRIKSSON, H.; BJORCK, I.; ANDERSSON, R.; LILJEBERG, H.; SILVERIO, J.; ELIASSON, A. Studies on $\alpha$-amylase degradation of retrograded starch gels from waxy maize and high-amylopectin potato. Carbohyd. Polym., v.43, p.81-87, 2000.

26 FREI, M.; SIDDHURAJU, P.; BECKER, K. Studies on the "in vitro" starch digestibility and the glycemic index of six different indigenous rice cultivars from the Philippines. Food Chem., v.83, p.395-402, 2003.

27 FUENTES-ZARAGOZA, E.; RIQUELME-NAVARRETE, M.J.; SÁNCHEZ-ZAPATA, E.; PÉREZ-ALVAREZ, J.A. Resistant starch as functional ingredient: a review. Food Res. Int., v.43, p.931-942, 2010.

28 GARCIA-ALONSO, A.; GOÑI, I. Effect of processing on potato starch: in vitro availability and glycaemic index. Starch/Starke, v.52, p.81-84, 2000.

29 GOÑI, I.; GARCÍA-DIZ, L.; MAÑAS, E.; SAURA-CALIXTO, F. Analysis of resistant starch: a method for foods and foods products. Food Chem., v.56, p.445-449, 1996.

30 GOÑI, I.; GARCIA-ALONSO, A.; GARCIA, D. Almidón resistente componente indigestible de la dieta alimentaria. Alimentaria, v.261, p.31-33, 1995.

31 HAMER, H.M.; JONKERS, D.; VENEMA, K.; VANHOUTVIN, S.; TROOST, F.J.; BRUMMER, R.J. Review article: the role of butyrate on colonic function. Aliment. Pharmacol. Ther., v.27, n.2, p.104-119, 2008.

32 HAN, K. H.; FUKUSHIMA, M.; KATO, T.; KOJIMA, M.; OHBA, K.; SHIMADA, K. et al. Sterol excretions and hepatic mRNA levels in rats. Lipids, v.38, n.9, p.919-924, 2003.

33 HAUB, M.D.; HUBACH, K.L.; AL-TAMIMI, E.K.; ORNELAS, S.; SEIB, P.A. Different types of resistant starch elicit different glucose responses in humans. J. Nutr. \& Metabol., v.2010, p.1-4, 2010.

34 HERNÁNDEZ, O.; EMALDI, U.; TOVAR, J. "In vitro" digestibility of edible films from various starch sources. Carbohyd. Polym., v.71, p.648-655, 2008.

35 HICKMAN, B.E.; JANASWAMY, S.; YAO, Y. Properties of starch subjected to partial gelatinization and betaamylolysis. J. Agric. Food Chem., v.28, p.666-674, 2009.

36 HOLM, J.; LUNDQUIST, I.; BJORCK, I.; ELIASSON, A. Degree of starch gelatinization, digestion rate of starch "in vitro", and metabolic response in rats. Am. J. Clin. Nutr., v.47, p.1010-1016, 1988.

37 HU, Y.; BLOCK, G.; NORKUS, E.P.; MORROW, J.D.; DIETRICH, M.; HUDES, M. Relations of glycemic index and glycemic load with plasma oxidative stress markers. Am. J. Clin. Nutr., v.84, p.70-76, 2006.

38 IKEOKA, D.; MADER, J.K.; PIEBER, T.R. Adipose tissue, inflammation and cardiovascular disease. Rev. Assoc. Med. Bras., v.56, p.116-121, 2010.

39 INSTITUTE OF MEDICINE (IOM). Food and Nutrition Board. Dietary references intake: proposed definition of dietary fiber. [s.I.], 2001.

40 JENKINGS, D.J.; KENDALL, C.W.; AUGUSTIN, L.S.; FRANCESCHI, S.; HAMIDI, M.; MARCHIE, A.; JENKINS, A.L.; AXELSEN, M. Glycemic index: overview of implications in health and disease. Am. J. Clin. Nutr., v.76, p.266S-273S, 2002.

41 JOBLING, S. Improving starch for food and industrial applications. Curr. Opin. Plant. Biol., v. 7, p. 210-218, 2004.

42 JUNG, E.Y.; SUH, H.J.; HONG, W.S.; KIM, D.G.; HONG, Y.H.; HONG, I.S.; CHANG, U.J. Uncooked rice of relatively low gelatinization degree resulted in lower metabolic glucose and insulin responses compared with cooked rice in female college students. Nutr. Res., v.29, p. 457-461, 2009. 
43 KEENAN, M.J.; ZHOU, J.; MCCUTCHEON, K. L.; RAGGIO, A. M.; BATEMAN, H. G.; TODD, E. et al. Effects of resistant starch, a non-digestible fermentable fiber, on reducing body fat. Obesity, v.14, p. 1523-1534, 2006.

44 KINGMAN, S.M.; ENGLYST, H.M. The influence of food preparation methods on the "in vitro" digestibility of starch in potatoes. Food Chem., v. 49, p.181-186, 1994.

45 LAJOLO, F. M.; MENEZES, E. W. Dietary fiber and resistant starch intake in Brazil: recommendations and actual consumption patterns. In: CHO, S. S.; DREHER, M. L. (ed.). Handbook of dietary fiber. New York: Marcel Dekker, 2001. p. 845-858.

46 LIU, H.; XIE, F.; YU, L.; CHEN, L.; LI, L. Thermal processing of starch-based polymers. Progr. Polym. Sci., v.34, p.1348-1368, 2009.

47 LOBO, A.R.; SILVA, G.M.L. Amido resistente e suas propriedades físico-químicas. Rev. Nutr., v.16, n.2, p.219226, 2003.

48 LOW, S.; CHIN, M.C.; DEURENBERG-YAP, M. Review on epidemic of obesity. Ann. Acad. Med. Singapore, v.38, p. 57-59, 2009.

49 MARINHO, M.C.S.; HAMANN, E.M.; LIMA, A.C.C.F. Práticas e mudanças no comportamento alimentar na população de Brasília, Distrito Federal, Brasil. Rev. Bras. Saúde Matern. Infant., v.7, p.251-261, 2007.

50 NUGENT, A.P. Health properties of resistant starch. Brit. Nutr. Found. Nutr. Bull., v.30, p.27-54, 2005.

51 PEREIRA, K.D. Amido resistente, a última geração no controle de energia e digestão saudável. Cien. Tecnol. Alim., v.27, p.88-92, 2007.

52 RAMOS, D.P.; LEONEL, M.; LEONEL, S. Amido resistente em farinhas de banana verde. Alim. Nutr., v.20, n.3, p.479-483, 2009.

53 SAJILATA, M.G.; SINGHAL, R.S. Specialty starches for snack foods. Carbohyd. Polym., v.59, p.131-151, 2005.

54 SAKUMA, M.; YAMANAKA-OKUMURA, H.; NANIWA, Y.; MATSUMOTO, D.; TSUNEMATSU, M.; YAMAMOTO, $\mathrm{H}$. Dose-dependent effects of barley cooked with white rice on postprandial glucose and desacyl ghrelin levels. J. Clin. \& Biochem. Nutr., v.44, p.151-159, 2009.

55 SHAMAI, K.; BIANCO-PELED, H.; SHIMONI, E. Polymorphism of resistant starch type III. Carbohyd. Polym., v.54, p.363-369, 2003.

56 SHARMA, A.; YADAV, B.S. Resistant starch: physiological roles and food applications. Food Rev. Int., v.24, p.193-234, 2008.

57 SINGH, J.; DARTOIS, A.; KAUR, L. Starch digestibility in food matrix: a review. Trends Food Sci. \& Technol., v.21, p.168-180, 2010.

58 SLAVIN, J. Whole grains and human health. Nutr. Res. Rev., v.17, p.99-110, 2004.

59 TAHVONE, R.; HIETANEN, R.M.; SIHVONEN, J.; SALMINEN, E. Influence of different processing methods on the glycemic index of potato (Nicola). J. Food. Comp. \& Anal., v.19, p.372-378, 2006.

60 TESTER, R.F.; KARKALAS, J.; QI, X. Starch - composition, fine structure and architecture. J. Cereal. Sci., v. 39 , p. $151-165,2004$.

61 THOMPSON, D.B. Strategies for the manufacture of resistant starch. Trends Food Sci. \& Technol., v.11, p.245-253, 2000.

62 TRUWELL, A.S. Glycemic index of foods. Eur. J. Clin. Nutr., v. 46, n.2, p. 91-101, 1992.

63 WALTER, M.; SILVA, L.P.; EMANUELLI, T. Amido resistente: características físico-químicas, propriedades fisiológicas e metodologias de quantificação. Ciência Rural, v.35, n.4, p. 975-980, 2005. 
64 WALTER, M.; SILVA, L.P.; PERDOMO, D.M.X. Biological response of rats to resistant starch. Rev. Inst. Adolfo Lutz, v. 64, n.2, p. 252-257, 2005.

65 WOLEVER, T.M.; JENKINS, D.J.A.; JENKINS, A.L.; JOSSE, R.G. The glycemic index: methodology and clinical implications. Am. J. Clin. Nutr., v.54, 846-854, 1991.

66 YUE, P.; WARING, S. Resistant starch in food applications. Cereal Food World, v.43, n.9, p. 690-695, 1998. 